\title{
Decompression Surgery Alone Versus Decompression Plus Fusion in Symptomatic Lumbar Spinal Stenosis
}

\author{
A Swiss Prospective Multicenter Cohort Study With 3 Years of Follow-up \\ Nils H. Ulrich, MD, ${ }^{*}$ Jakob M. Burgstaller, MD, DMD, ${ }^{\dagger}$ Giuseppe Pichierri, PhD, ${ }^{\dagger}$ \\ Maria M. Wertli, MD, PhD, ${ }^{\dagger, \ddagger}$ Mazda Farshad, MD, MPH, ${ }^{\S}$ François Porchet, MD, ${ }^{*}$ Johann Steurer, MD, ${ }^{\dagger}$ \\ and Ulrike Held, $\mathrm{PhD}^{\dagger}$, on behalf of the LSOS Study Group
}

Study Design. Retrospective analysis of a prospective, multicenter cohort study.

Objective. To estimate the added effect of surgical fusion as compared to decompression surgery alone in symptomatic lumbar spinal stenosis patients with spondylolisthesis.

Summary of Background Data. The optimal surgical management of lumbar spinal stenosis patients with spondylolisthesis remains controversial.

Methods. Patients of the Lumbar Stenosis Outcome Study with confirmed DLSS and spondylolisthesis were enrolled in this study. The outcomes of this study were Spinal Stenosis Measure (SSM) symptoms (score range 1-5, best-worst) and function (14) over time, measured at baseline, 6, 12, 24, and 36 months follow-up. In order to quantify the effect of fusion surgery as compared to decompression alone and number of decompressed levels, we used mixed effects models and accounted for the repeated observations in main outcomes (SSM symptoms and

From the *Department of Orthopedics and Neurosurgery, Spine Center, Schulthess Clinic, Zurich, Switzerland; ' ${ }^{\dagger}$ Horten Centre for Patient Oriented Research and Knowledge Transfer, University of Zurich, Zurich, Switzerland; ${ }^{\ddagger}$ Division of General Internal Medicine, Bern University Hospital, Bern University, Bern, Switzerland; and \$Spine Division, Balgrist University Hospital, University of Zurich, Zurich, Switzerland.

Acknowledgment date: October 7, 2016. First revision date: November 6, 2016. Second revision date: November 30, 2016. Acceptance date: December 5, 2016.

Drs Ulrich and Burgstaller have contributed equally to this work.

The manuscript submitted does not contain information about medical device(s)/drug(s).

The Baugarten Foundation, the Helmut Horten Foundation, the PfizerFoundation for geriatrics and research in geriatrics, the Symphasis Charitable Foundation, and the OPO Foundation funds were received in support of this work.

No relevant financial activities outside the submitted work.

Address correspondence and reprint requests to Nils $\mathrm{H}$. Ulrich, MD, Department of Orthopedics and Neurosurgery, Spine Center, Schulthess Clinic, Lengghalde 2, 8008 Zurich, Switzerland;

E-mail: nils.hb.ulrich@gmail.com

DOI: 10.1097/BRS.0000000000002068
SSM function) over time. In addition to individual patients random effects, we also fitted random slopes for follow-up time points and compared these two approaches with Akaike's Information Criterion and the chi-square test. Confounders were adjusted with fixed effects for age, sex, body mass index, diabetes, Cumulative Illness Rating Scale musculoskeletal disorders, and duration of symptoms.

Results. One hundred thirty-one patients undergoing decompression surgery alone $(n=85)$ or decompression with fusion surgery $(n=46)$ were included in this study. In the multiple mixed effects model the adjusted effect of fusion compared with decompression alone surgery on SSM symptoms was 0.06 (95\% confidence interval: $-0.16-0.27)$ and -0.07 (95\% confidence interval: $-0.25-0.10)$ on SSM function, respectively.

Conclusion. Among the patients with degenerative lumbar spinal stenosis and spondylolisthesis our study confirms that in the two groups, decompression alone and decompression with fusion, patients distinctively benefited from surgical treatment. When adjusted for confounders, fusion surgery was not associated with a more favorable outcome in both SSM scores as compared to decompression alone surgery.

Key words: decompression, degenerative lumbar spinal stenosis, fusion, laminectomy, laminotomy, lumbar fusion, mixed effects models, multicenter, multilevel, surgery.

Level of Evidence: 3

Spine 2017;42:E1077-E1086

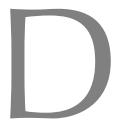

egenerative lumbar spinal stenosis (DLSS) is a narrowing of the spinal canal by surrounding bone and soft tissues that compromise neural structures. Radiographic findings of spinal stenosis are highly prevalent ${ }^{1}$ and $85 \%$ of patients typically present with significant long-term symptoms of intermittent neurogenic claudication such as gluteal and/or lower extremity pain and fatigue that may occur with or without back pain., ${ }^{2,3}$ When conservative treatment fails, patients are usually referred to surgical treatment. The aim of surgery is to decompress

www.spinejournal.com E1077 
the spinal canal and dural sac from degenerative bony and ligamentous overgrowth.

As a result, the number of surgical procedures performed for DLSS has increased steadily over the years $(e . g$., the rates of complex fusion surgery had a 15 -fold increase between 2002 and 2007), with costs reaching USD \$1.65 billion per year. ${ }^{4}$ For instance, in the metropolitan area of Zurich with approximately 1.5 million inhabitants approximately 1750 lumbar decompression surgeries and decompression with fusion surgeries are done every year (Department of Health, Canton of Zurich, 2016, personal communication in September 2016).

There is still a large variation in surgical management chosen by different surgeons and institutions, 5,6 and no strong superiority of one technique over the other has been identified yet. $^{7-10}$ Currently, surgical management for degenerative DLSS includes decompression with or without lumbar fusion. ${ }^{11}$ Simple decompression surgery alone has been proven to be beneficial in patients with DLSS. ${ }^{12-15}$ Other studies showed that the addition of fusion might be valuable for patients' outcome. ${ }^{16-18}$

The aim of the study was to estimate the added effect of surgical fusion as compared to decompression surgery alone in symptomatic lumbar spinal stenosis patients with spondylolisthesis.

\section{MATERIALS AND METHODS}

\section{Study Design}

For this retrospective analysis we did use data from the Lumbar Stenosis Outcome Study (LSOS). The LSOS is conducted as a prospective cohort study at eight medical centers (with approximately two million inhabitants in the over regional area) covered by Rheumatology and Spine Surgery Units in Switzerland. Patients with a history of neurogenic claudication and lumbar spinal stenosis verified by magnetic resonance imaging (MRI) or computed tomography were eligible. Patients had no evidence of stenosis caused by tumor, fracture, infection, or significant deformity $\left(>15^{\circ}\right.$ lumbar scoliosis, diagnosed on conventional x-ray with anterior-posterior and lateral views), and were aged 50 years or more. Furthermore, patients had no clinical peripheral artery occlusive disease (confirmed by a vascular specialist in patients without palpable pulses in the lower limb). The decision of the treatment strategy (conservative or surgical) was made by the patient and his attending physician. Patients were assessed for eligibility between December 2010 and December 2015, and will be followed up 3 years.

\section{Patient Population}

All patients who met inclusion criteria, underwent surgery on one or two adjacent levels with degenerative spondylolisthesis (DS, step $>3 \mathrm{~mm}$, evaluated in MRI, flexion-extension radiographs were not obtained), and had at least 12 months follow-up were eligible. Furthermore, none of the patients had prior lumbar spine surgery.

\section{Surgical Interventions}

All patients underwent either decompression alone (decompression alone group) or decompression with fusion (fusion group). Decompression surgery consisted of a standard open or microscopic posterior lumbar decompression of the affected level(s). Decompression of the lateral recess and the foramina was performed when necessary to decompress the exiting nerve roots. Fusion surgery consisted besides decompression surgery of additional implantation of pedicle screws with rods, and intersomatic fusion and cage(s) at the affected level(s). The decision to add fusion and to proceed with single compared with multilevel procedures was based on the surgeon's discretion. The procedures were done or supervised by senior neuro- or orthopedic surgeons with more than 10 years of experience after board certification.

\section{Radiological Classification}

The MRI of each patient was evaluated by two senior radiologists. They categorized the severity of the central stenosis of each level into "no," "mild," "moderate," or "severe," and lateral recess and foraminal stenosis into grade 0 to 3 according to the consensus paper on core radiological parameters of the LSOS. ${ }^{19}$

\section{Data Collection and Follow-up}

Parts of the basic data sheet were interview-administered and recorded by a study coordinator. All other questionnaires were self-administered and completed by the patients themselves. All data were collected at baseline, and at 6 months. Long-term outcome data were gathered after 1, 2, and 3 years.

The study coordinator checked all questionnaires after receiving for completeness. In case of missing data, he called the patient and tried to collect the missing data.

Data were entered independently and in duplicate in two databases that were crosschecked. Any discrepancies were identified and rechecked in the original files.

\section{Questionnaires}

Spinal Stenosis Measure (SSM): The SSM, an instrument specifically developed for spinal stenosis patients by Stucki et $a l,{ }^{20}$ targets to measure severity of symptoms and quantifies disability of the lumbar spinal stenosis population. It is recommended by the North American Spine Society and used in different studies on lumbar spinal stenosis. ${ }^{21-24}$ It consists of three different subscales; the Symptom Severity Subscale, the Physical Function Subscale, and the Satisfaction Subscale. The symptom severity scale can be divided into a pain domain (severity, frequency, and back pain) and a neuroischemic domain (leg pain, weakness, numbness, and balance disturbance). Score range is from 1 to 5 and 1 to 4 (best-worst), respectively.

Feeling Thermometer and Numeric Rating Scale: General assessment of lumbar spinal stenosis symptoms such as lower extremity pain and discomfort are measured. Score range is from 0 to 100 and 0 to 10 (best-worst), respectively. 
EQ-5D-3L: The EQ-5D-3L is an assessment tool to measure health-related quality of life. It measures general non-disease-specific health-related quality of life, including physical, mental, and social dimensions. ${ }^{25}$ The health status measures five dimensions of health (mobility, self-care, usual activities, pain/discomfort, and anxiety/depression), which can be calculated as a sum score (score range $0-100$, worst-best). ${ }^{25}$ The second part of the questionnaire estimates patient's actual health status (score range $0-100$, worst-best).

Roland and Morris Disability Questionnaire (RMDQ): The RMDQ is a back pain-specific, self-rated physical disability questionnaire developed by Roland and Morris in $1983 .{ }^{26}$ Disability is measured with respect to the following categories: physical function activities and activities of daily living including eating and sleeping. Score range is from 0 to 24 (best-worst).

Cumulative Illness Rating Scale (CIRS): Comorbidity is measured using CIRS that rates the presence and severity of comorbid diseases in 14 organ systems (according to modified version by Miller $e t a l^{27}$ ). Score range is from 0 to 56 (best-worst). The musculoskeletal organ system (CIRS musculoskeletal disorders) was separately included in the analysis. Score range is from 0 to 4 (best-worst).

\section{Outcomes}

The outcomes of this study were SSM symptoms and SSM function over time. These outcomes were measured at baseline, 6, 12, 24, and 36 months follow-up.

Further outcomes of interest were Numeric Rating Scale, Feeling Thermometer, EQ-5D-EL sum score and actual health status, and RMDQ at 12 months follow-up.

\section{Ethics}

This multicenter cohort study was conducted in compliance with all international laws and regulations and any applicable guidelines. Written informed consent to participate in the study has been obtained from participants. The study was approved by the independent Ethics Committee of the Canton Zurich (KEK-ZH-NR: 2010-0395/0).

\section{Sample Size Considerations}

We calculated that a minimum of 44 patients with baseline and 12 months follow-up in each treatment group-the decompression alone group and fusion group-would be required for the study to have $80 \%$ power to detect a clinical relevant difference in change in SSM symptoms of 0.48 at a significance level of $0.05 .^{20}$ The standard deviation (SD) was assumed to be 0.8 (Ulrich et al., ${ }^{28}$ accepted for publication in Clinical Spine Surgery) in both treatment groups. Imbalance in baseline characteristics between treatment groups were adjusted for within the regression framework.

\section{Statistical Analyses}

Analysis of data consisted of descriptive statistics of patient demographics and outcomes at baseline. Continuous variables were shown as mean and SD, and categorical variables were shown as numbers and percentages of total, stratified by decompression alone and decompression with fusion. Scatterplots were used to display changes in main outcomes over follow-up time and to display the correlation structure of the repeated measurements over time.

In order to quantify the effect of fusion surgery as compared to decompression alone and number of decompressed levels, we used mixed effects models and accounted for the repeated observations in main outcomes (SSM symptoms and SSM function) over time. In addition to individual patients' random effects, we also fitted random slopes for follow-up time points and compared these two approaches with Akaike's Information Criterion (AIC) and the chi-square test. Confounders were adjusted for with fixed effects for age, sex, body mass index (BMI), diabetes, CIRS musculoskeletal disorders, and duration of symptoms. Continuous confounders were centered before inclusion to simplify interpretation of the intercept term. Conservative $P$ values for the fixed effects were calculated as proposed by Kenward and Roger. ${ }^{29}$ The level of significance was set to $5 \%$.

All analyses were conducted with $\mathrm{R}$ for Windows. ${ }^{30}$

\section{RESULTS}

\section{Patient Characteristics}

Between December 2010 and December 2015 approximately 1716 patients were potentially eligible, 853 patients agreed to participate, and 724 patients had no prior lumbar spine surgery (Figure 1, study flow). Of these, 443 patients underwent decompression surgery alone or decompression with fusion surgery within the first 6 months after baseline. For this study, 131 patients met the inclusion criteria (Figure 1).

In Table 1 we present the patients' baseline characteristics; $85(65 \%)$ patients underwent decompression alone and $46(35 \%)$ patients underwent decompression with fusion. Baseline characteristics were remarkably similar; however, patients in the fusion group were slightly younger (mean age $68 v s 75.4 \mathrm{yr}$ in the decompression alone group). There were no other statistically significant differences in baseline characteristics.

Overall, 76 of 131 patients $(58 \%)$ were women, and mean BMI was $26.8 \mathrm{~kg} / \mathrm{m}^{2}$ (SD 4.5). Seventeen patients had diabetes $(13 \%)$ and $23(17.6 \%)$ were current smokers. Fiftytwo patients $(61.2 \%)$ had previous lumbar epidural steroid injections in the decompression alone group, and 28 patients $(60.9 \%)$ in the fusion group.

Four variables (duration of symptoms, EQ-5D-EL sum score and actual health status, and RMDQ) had a small percentage of missing values at baseline and/or 12 months follow-up (ranging from $0.75 \%$ to $1.5 \%$ ).

\section{Surgical Characteristics}

Most patients in both groups were operated on the L4/L5 level $(84.7 \%$ in the decompression alone and $82.6 \%$ in the fusion group, respectively). Furthermore, no patient had 


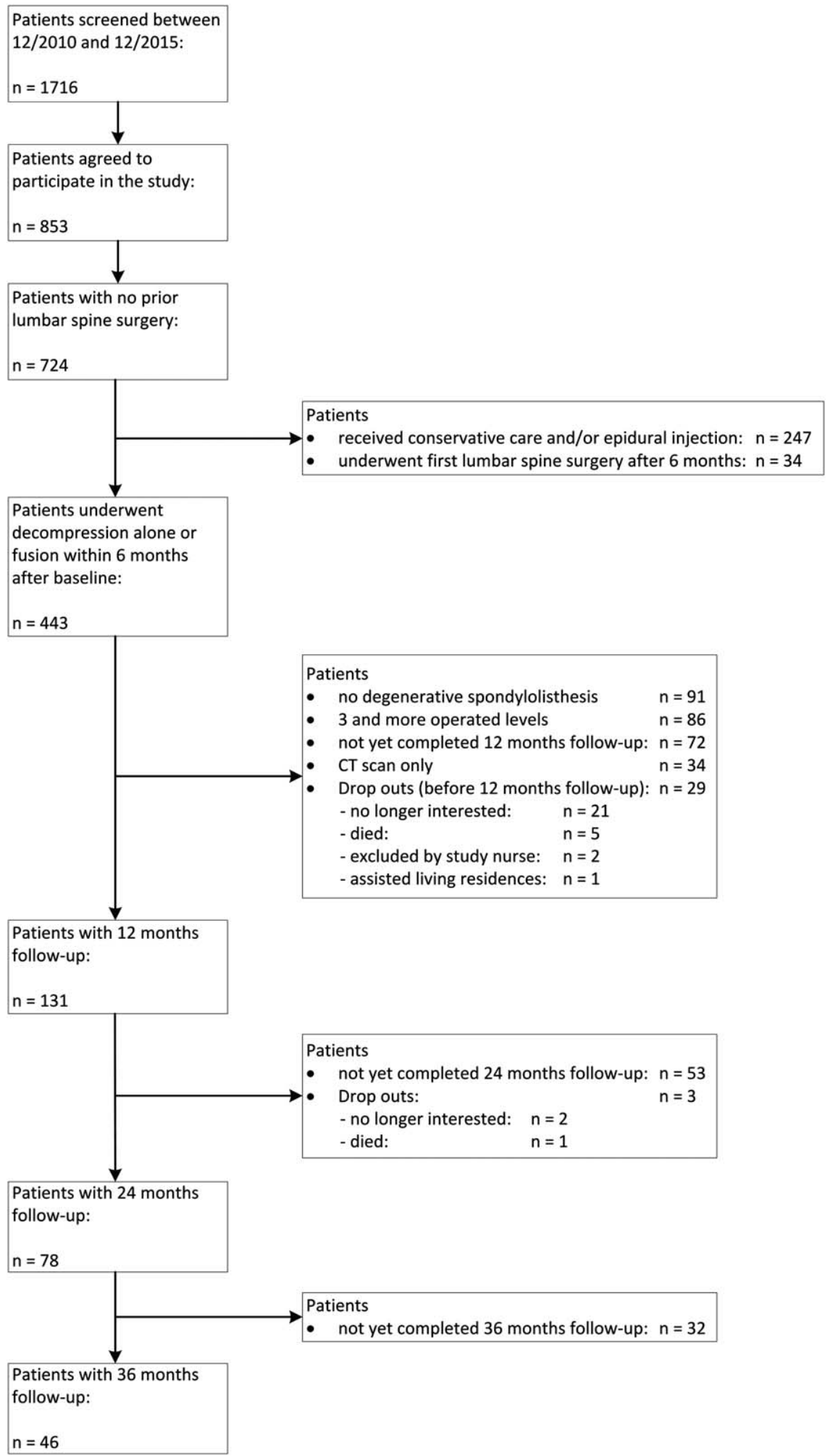

Figure 1. Study flow.

surgery on the level L1/L2. In the decompression alone group, $83.5 \%$ of the patients were operated microscopically, whereas in the fusion group only $54.3 \%$ of the patients were operated microscopically (Table 2).

In the decompression alone group, most patients had three or four moderate- or severe-level stenoses $(31.8 \%$ and $30.6 \%$, respectively), and $20 \%$ had two. In the fusion group, $28.3 \%$ of the patients had three moderateor severe-level stenoses, $26.1 \%$ had two, and $28.3 \%$ had one (Table 2).

In the fusion group, 39 patients were treated with transpedicular screws with rods and intersomatic cages, and 


\begin{tabular}{|c|c|c|c|}
\hline Characteristics & $\begin{array}{l}\text { Decompression Alone } \\
(\mathbf{n}=\mathbf{8 5})\end{array}$ & $\begin{array}{c}\text { Fusion } \\
(\mathbf{n}=46)\end{array}$ & $\boldsymbol{P}$ \\
\hline Age, mean (SD) (yr) & $75.4(7.6)$ & $68.0(7.8)$ & $<0.001$ \\
\hline Female, $\mathrm{n}(\%)$ & $53(62.4)$ & $23(50)$ & 0.237 \\
\hline BMI, mean $(\mathrm{SD})\left(\mathrm{kg} / \mathrm{m}^{2}\right)$ & $26.5(4.7)$ & $27.4(4)$ & 0.309 \\
\hline Diabetes, n (\%) & $14(16.5)$ & $3(6.5)$ & 0.179 \\
\hline Smoker, n (\%) & $12(14.1)$ & $11(23.9)$ & 0.244 \\
\hline Level of education, $\mathrm{n}(\%)$ & & & 0.521 \\
\hline Compulsory education (1-9 yr) & $24(28.2)$ & $11(23.9)$ & \\
\hline $\begin{array}{l}\text { Higher education/vocational training (no } \\
\text { university) }(10-12 \mathrm{yr})\end{array}$ & $52(61.2)$ & $27(58.7)$ & \\
\hline University degree & $9(10.6)$ & $8(17.4)$ & \\
\hline Work status, n (\%) & & & 0.065 \\
\hline Full- or part-time & $7(8.2)$ & $11(23.9)$ & \\
\hline Retired & $76(89.4)$ & $33(71.7)$ & \\
\hline Other & $2(2.4)$ & $2(4.4)$ & \\
\hline Duration of symptoms, n (\%) & & & 0.138 \\
\hline$<3 \mathrm{mo}$ & $6(7.1)$ & $3(6.5)$ & \\
\hline $3-6 \mathrm{mo}$ & $18(21.2)$ & $4(8.7)$ & \\
\hline $6-12 \mathrm{mo}$ & $16(18.8)$ & $5(10.9)$ & \\
\hline$>12 \mathrm{mo}$ & $44(51.8)$ & $34(73.9)$ & \\
\hline Not available & $1(1.2)$ & $0(0)$ & \\
\hline CIRS, mean (SD) & $9.1(3.7)$ & $8.9(3.9)$ & 0.83 \\
\hline CIRS musculoskeletal disorders, mean (SD) & $2.0(0.5)$ & $1.9(0.4)$ & 0.649 \\
\hline SSM symptoms, mean (SD) & $3.2(0.6)$ & $3.2(0.6)$ & 0.986 \\
\hline SSM functions, mean (SD) & $2.3(0.7)$ & $2.1(0.5)$ & 0.159 \\
\hline NRS, mean (SD) & $6.6(2.1)$ & $6.6(1.6)$ & 0.917 \\
\hline $\mathrm{FT}$, mean $(\mathrm{SD})$ & $66.2(21.6)$ & $65.5(17.6)$ & 0.842 \\
\hline EQ-5D-EL sum score, mean (SD) & $66.9(17.5)$ & $66.7(10.9)$ & 0.924 \\
\hline EQ-5D-EL actual health status, mean (SD) & $63.3(26.4)$ & $56.0(19.3)$ & 0.108 \\
\hline RMDQ, mean (SD) & $12.5(5.5)$ & $12.1(4.6)$ & 0.679 \\
\hline Prior lumbar epidural steroid injection, $\mathrm{n}(\%)$ & $52(61.2)$ & $28(60.9)$ & 0.999 \\
\hline
\end{tabular}

seven patients were treated the same way but without cage implantation.

\section{Intra- and Postoperative Complications, Reoperations}

Two patients $(2.4 \%)$ in the decompression alone group and one patient $(2.2 \%)$ in the fusion group experienced a durotomy during the surgery (Table 3 ). No patient in the decompression alone group and one patient $(2.2 \%)$ in the fusion group had a postoperative wound infection. Other postoperative complications (e.g., urosepsis, hemorrhage, wound healing deficit) were seen in $6 \%$ and $6.6 \%$ of the patients, respectively. None of these differences were statistically significant. Furthermore, no patient died within 6 months postoperatively.

Reoperations were performed in eight patients (9.4\%) in the decompression alone group (one patient underwent two reoperations) and two patients $(4.3 \%)$ in the fusion group (Table 3). Mean time to the second surgery was 192 days (range 8-565) in the decompression alone group and 280 days (range 33-527) in the fusion group. Six $(75 \%)$ of the initially decompressed only patients underwent a fusion procedure during second surgery.

\section{Further Outcomes at 12 Months Follow-up}

All patients improved from baseline to 12 months follow-up (Appendix Table 1, http://links.lww.com/BRS/B248). The patients of the fusion group improved more than the patients in the decompression alone group; however, factors influencing the treatment decisions were not accounted for these raw data.

\section{Repeated Measurements Analysis for Main Outcomes}

\section{Spinal Stenosis Measure Symptoms}

Graphical display of SSM symptoms from baseline to 36 months revealed a strong overall decrease from baseline to 6 months, a slighter decrease from 6 to 12 months, and 


\begin{tabular}{|c|c|c|c|}
\hline Outcome & $\begin{array}{c}\text { Decompression Alone } \\
(\mathbf{n}=\mathbf{8 5})\end{array}$ & Fusion $(n=46)$ & $\boldsymbol{P}$ \\
\hline \multicolumn{4}{|l|}{ Decompression level, n (\%) } \\
\hline L2/L3 & $5(5.9)$ & $1(2.2)$ & 0.595 \\
\hline $\mathrm{L} 3 / \mathrm{L} 4$ & $53(62.4)$ & $10(21.7)$ & $<0.001$ \\
\hline L4/L5 & $72(84.7)$ & $38(82.6)$ & 0.95 \\
\hline L5/S1 & $6(7.1)$ & $5(10.9)$ & 0.674 \\
\hline Levels decompressed, n (\%) & & & 0.019 \\
\hline 1 & $34(40)$ & $29(63)$ & \\
\hline 2 & $51(60)$ & $17(37)$ & \\
\hline OP technique, n (\%) & & & 0.001 \\
\hline Conventional & $13(15.3)$ & $21(45.7)$ & \\
\hline Microscopic & $71(83.5)$ & $25(54.3)$ & \\
\hline Not available & $1(1.2)$ & $0(0)$ & \\
\hline $\begin{array}{l}\text { Number of moderate/severe } \\
\text { levels, } \mathrm{n}(\%)\end{array}$ & & & $<0.001$ \\
\hline 1 & $2(2.4)$ & $13(28.3)$ & \\
\hline 2 & $17(20)$ & $12(26.1)$ & \\
\hline 3 & $27(31.8)$ & $13(28.3)$ & \\
\hline 4 & 26 (30.6) & $4(8.7)$ & \\
\hline 5 & $13(15.3)$ & $4(8.7)$ & \\
\hline
\end{tabular}

remained fairly constant on the low level up to 36 months (Figure 2A, left), as depicted by the corresponding loess curve. The pattern of the fusion group was similar to the overall trend, whereas there was a slight increase in the decompression group between 12 and 36 months (Figure 2A; right and center).
The mixed effects model was fitted with random patient effects and with random slopes over time. When comparing the models, the AIC was in favor of the more complex random slopes model (chi-square $P<0.001$ ). Table 4 shows the adjusted effect of fusion compared with decompression alone surgery on SSM symptoms, which is estimated to be

\section{TABLE 3. Intra- and Postoperative Complications, Reoperations}

\section{Outcome}

Intraoperative complications, $\mathrm{n}(\%)$

\begin{tabular}{|l|}
\hline Intraoperative complications, $\mathrm{n}$ \\
\hline Vascular injury \\
\hline Other \\
\hline None \\
\hline Postoperative complications, $\mathrm{n}(\%$ \\
\hline Wound infection \\
\hline Osseous infection \\
\hline Other \\
\hline None \\
\hline $\begin{array}{l}\text { Postoperative mortality (death } \\
\text { within } 6 \text { wk of surgery) } \mathrm{n}(\%)\end{array}$ \\
\hline $\begin{array}{l}\text { Postoperative mortality (death } \\
\text { within } 3 \text { mo of surgery) } \mathrm{n}(\%)\end{array}$ \\
\hline $\begin{array}{l}\text { Reoperation, indication for } \\
\text { second surgery }\end{array}$ \\
\hline $\begin{array}{c}\text { Restenosis/foraminal stenosis } \\
\text { (index level) }\end{array}$ \\
\hline Adjacent segment stenosis \\
\hline Infection \\
\hline Back pain \\
\hline
\end{tabular}

\section{Decompression Alone} $(\mathbf{n}=\mathbf{8 5})$

Fusion $(n=46)$

\begin{tabular}{|c|c|}
\hline & $0(0)$ \\
\hline & $0(2.4)$ \\
\hline$\%)$ & $83(97.6)$ \\
\hline $0(0)$ \\
$0(0)$ \\
\hline $5(6)$ \\
\hline $0(04)$ \\
\hline $0(0)$ \\
\hline $7(8.2)$ \\
\hline $1(1.2)$ \\
$0(0)$ \\
$1(1.2)$ \\
\end{tabular}

\begin{tabular}{|c|c|}
\hline $0(0)$ & \\
\hline $1(2.2)$ & 0.759 \\
\hline $0(0)$ & \\
\hline 45 (97.8) & \\
\hline $1(2.2)$ & 0.302 \\
\hline $0(0)$ & \\
\hline 3 (6.6) & 0.409 \\
\hline 43 (93.4) & \\
\hline $0(0)$ & \\
\hline $0(0)$ & \\
\hline & 0.135 \\
\hline $1(2.2)$ & \\
\hline $0(0)$ & \\
\hline $1(2.2)$ & \\
\hline $0(0)$ & \\
\hline
\end{tabular}



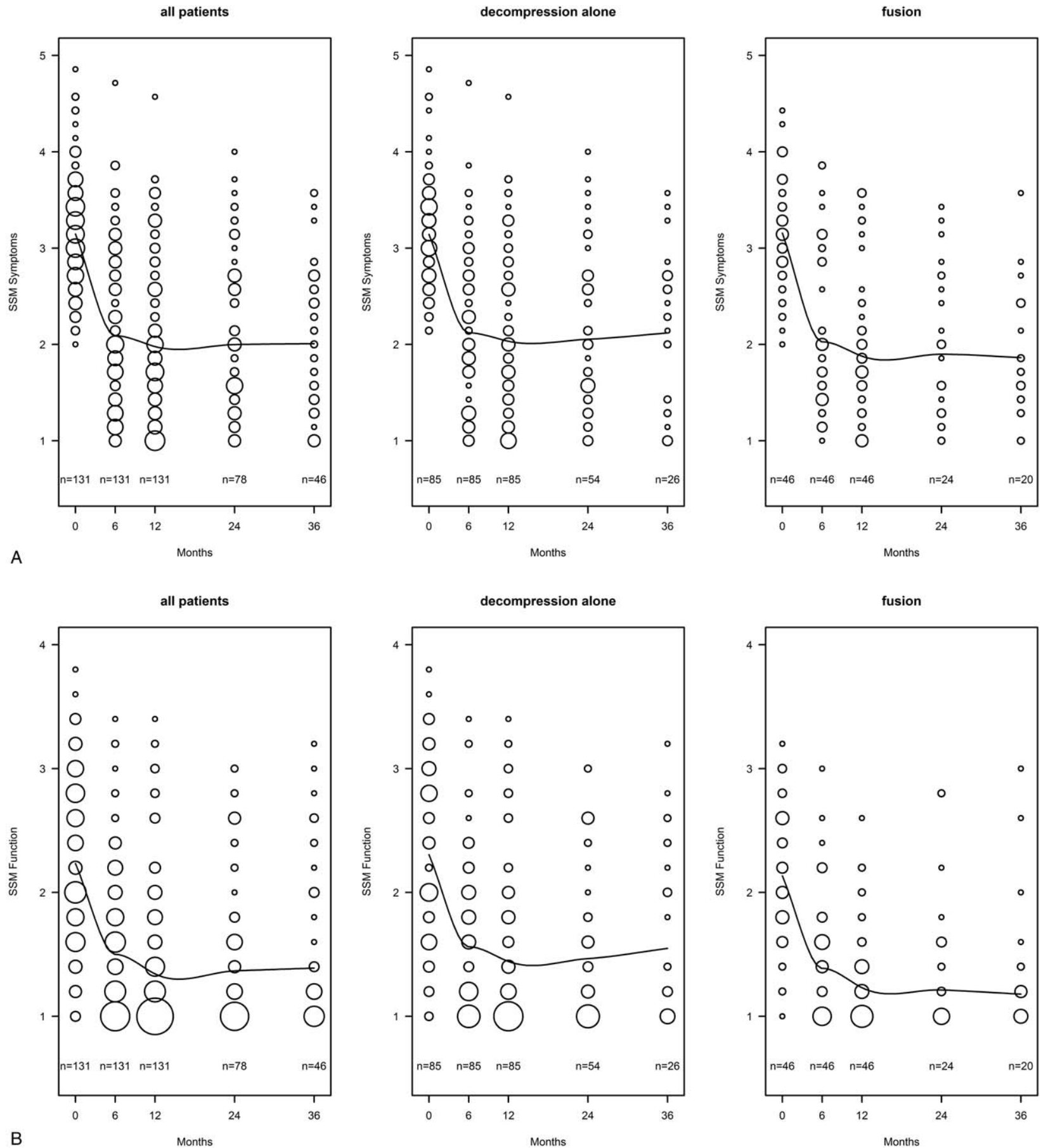

Figure 2. A, SSM symptoms score is displayed against time. The size of the bubbles represents the number of patients with the specific SSM symptoms score value. The overall trend is displayed by the solid black line, a smoothed estimate of the overall trend. The left most figure is based on all patients, the middle figure is based on patients with decompression alone, and the right most figure is based on patients with fusion. B, SSM function score is displayed against time. The size of the bubbles represents the number of patients with the specific SSM function score value. The overall trend is displayed by the solid black line, a smoothed estimate of the overall trend. The left most figure is based on all patients, the middle figure is based on patients with decompression alone, and the right most figure is based on patients with fusion. SSM indicates Spinal Stenosis Measure.

0.06 (95\% confidence interval [CI]: $-0.16-0.27)$. On average, patients improved (decreased) by 1 point in SSM symptoms from baseline to 6 months follow-up. The improvement persisted at 12,24 , and 36 months (1.11, 1.10 , and 1.16 points, respectively). The improvement is larger than the established clinically meaningful change in
SSM symptoms (0.48 points). ${ }^{20}$ The confounders were 2- versus 1-level decompression surgery, age, sex, BMI category, diabetes, CIRS musculoskeletal disorder subscore, and duration of symptoms before baseline in this model. Estimated random effects (bullet points) and slopes (small lines) were plotted against age at baseline in Appendix 


\begin{tabular}{|c|c|c|c|}
\hline Coefficients & Estimate & SE & $\boldsymbol{P}$ \\
\hline (Intercept) & 3.03 & 0.184 & $<0.001$ \\
\hline Fusion & 0.06 & 0.107 & 0.599 \\
\hline \multicolumn{4}{|c|}{ Change from baseline to ... } \\
\hline $6 \mathrm{mo}$ & -1.00 & 0.066 & $<0.001$ \\
\hline $12 \mathrm{mo}$ & -1.11 & 0.066 & $<0.001$ \\
\hline $24 \mathrm{mo}$ & -1.10 & 0.085 & $<0.001$ \\
\hline $36 \mathrm{mo}$ & -1.16 & 0.112 & $<0.001$ \\
\hline \multicolumn{4}{|c|}{ 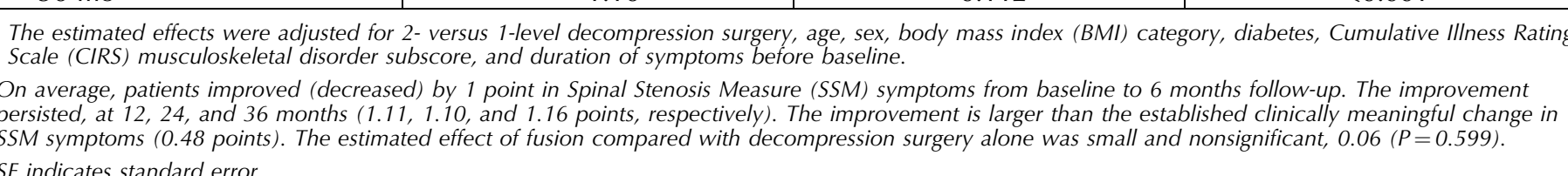 } \\
\hline
\end{tabular}

Figure 1a, http://links.lww.com/BRS/B248. It showed that older patients with higher levels of SSM symptoms developed slightly less favorable than the general decreasing trend.

\section{Spinal Stenosis Measure Function}

Graphical representation of SSM function showed an overall decrease from baseline to 36 months (Figure 2B, left). A similar pattern as in SSM symptoms was visible in the clinical courses across patients with fusion and decompression alone surgery (Figure 2B, right and center). When we fitted two mixed effects models, one with random patient effects and one with random slopes over time, we found that the AIC was smaller for the more complex model (chi-square $P=0.048$ ). The estimated effect of fusion compared with decompression alone surgery on SSM function was - 0.07 (95\% CI: - 0.250.10 ) (Table 5) when adjusting for the confounders 2- compared with 1-level decompression surgery, age, sex, BMI category, diabetes, CIRS musculoskeletal disorder subscore, and duration of symptoms before baseline. On average, patients improved (decreased) by 0.66 points in SSM function from baseline to 6 months follow-up. Improvement over time increased at 12,24 , and 36 months $(0.79,0.75,0.71$ points, respectively). The improvement considered clinically meaningful is 0.52 points for SSM function. ${ }^{20}$
Estimated random effects (bullet points) and slopes (small lines) of this model were plotted against age at baseline in Figure Appendix 1b, http://links.lww.com/ BRS/B248.

\section{DISCUSSION}

The present study examined the effect of decompression alone compared with decompression with fusion surgery in patients with symptomatic DLSS and DS. Our results demonstrated that both groups distinctly benefited from surgical treatment and the positive effect persisted over 3-year follow-up period. When adjusted for confounders, fusion surgery was not associated with a more favorable outcome in both SSM scores as compared to decompression alone surgery.

Our results were in line with a quite recently published randomized controlled trial (RCT) by Forsth et al. ${ }^{15}$ In their trial the baseline SSM symptoms and function scores were comparable to our patient groups and after 2 years followup, they reported no significant differences in both scores between decompression surgery with fusion and decompression alone surgery in patients with DS. In a retrospective study from 2013 with more than 5390 patients (with and without spondylolisthesis) by Forsth et al, ${ }^{31}$ the authors

\section{TABLE 5. Final Random Slopes Model for Spinal Stenosis Measure Function}

\begin{tabular}{|c|c|c|c|}
\hline Coefficients & Estimate & SE & $\boldsymbol{P}$ \\
\hline (Intercept) & 2.30 & 0.15 & $<0.001$ \\
\hline Fusion & -0.07 & 0.087 & 0.414 \\
\hline \multicolumn{4}{|c|}{ Changes from baseline to ... } \\
\hline $6 \mathrm{mo}$ & -0.66 & 0.057 & $<0.001$ \\
\hline $12 \mathrm{mo}$ & -0.79 & 0.056 & $<0.001$ \\
\hline $24 \mathrm{mo}$ & -0.75 & 0.068 & $<0.001$ \\
\hline $36 \mathrm{mo}$ & -0.71 & 0.086 & $<0.001$ \\
\hline \multicolumn{4}{|c|}{$\begin{array}{l}\text { The estimated effects were adjusted for 2- versus 1-level decompression surgery, age, sex, body mass index (BMI) category, diabetes, Cumulative IIIness Rating } \\
\text { Scale (CIRS) musculoskeletal disorder subscore, and duration of symptoms before baseline. } \\
\text { On average, patients improved (decreased) by } 0.66 \text { points in Spinal Stenosis Measure (SSM) function from baseline to } 6 \text { months follow-up. Improvement over } \\
\text { time increased at 12, } 24 \text {, and } 36 \text { months }(0.79,0.75 \text {, and } 0.71 \text { points, respectively). The improvement considered clinically meaningful is } 0.52 \text { points for SSM } \\
\text { function. Fusion compare with decompression alone had a small and nonsignificant effect of }-0.07(P=0.414) \text {. }\end{array}$} \\
\hline
\end{tabular}


identified no patient-reported differences between the decompression only group and the fusion group 2 years postoperatively. Athiviraham et $a l^{32}$ came to a similar conclusion in their cohort study with 96 patients at 2 years follow-up.

Ghogawala et al, ${ }^{18}$ on the contrary, reported in their RCT a significantly greater and clinically meaningful improvement in patients with DS who underwent decompression with fusion compared with decompression alone. These results are in contrast to our findings; however, they reported an improvement only in the physical-component summary of the Medical Outcomes Study 36-Item ShortForm Health Survey (SF-36). The SF-36 is a generic outcome measure that does not measure specific neuroischemic features of DLSS, which may be the dominant symptoms. ${ }^{33}$ Furthermore, more patients underwent reoperation in the decompression alone group. This might have had a negative effect on the physical-component summary score of SF-36 during the time from initial to secondary surgery.

Fusion surgery is associated with increased risk of major complications (i.e., acute myocardial infarct, respiratory failure, pneumonia) ${ }^{4}$ and higher infection rates due to osteosynthesis material. Furthermore, the longer operating times of fusion compared with decompression alone surgery increase the risks of anesthesia and their consequences in the typical elderly lumbar spinal stenosis patient population. In these patients osteopenia or osteoporosis is also a common concomitant disease that increases the risk of screw loosening and sinking of the intersomatic cage. Nevertheless, surgeons use more and more fusion procedures ${ }^{4}$ with the aim of preventing possible postoperative instability-especially if DS is present-despite the lack of a broadly accepted definition of this term. ${ }^{34}$ The approach of treating patients with DS with decompression and fusion is based on the results of a landmark study by Herkowitz and Kurz ${ }^{17}$ from 1991 and subsequent long-term results of the same cohort. ${ }^{35}$ This cohort was, however, small $(\mathrm{n}=50)$, not randomized, did not address potential confounders or different techniques of fusion, and did not use validated measures of treatment success. Moreover, only little new evidence has emerged to justify the increased risks and costs that are associated with fusion since these studies. ${ }^{36}$

Fusion procedures are also associated with increased resource use. ${ }^{4}$ Costs of fusion surgery are twice as expensive in Switzerland (diagnosis-related groups, SwissDRG standard treatment costs) and the estimated hospital stay is longer.

The main strength of the present study was that only patients who underwent surgery on one or two adjacent levels and DS were included. The present study was designed to give us the opportunity to evaluate the effect of decompression alone compared with decompression with fusion surgery very specifically. The mixed models approach did adjust for the differences in age and other potential confounders at baseline, which otherwise would have affected the results. Display of "raw" data might be useful for understanding differences in outcomes. As in nonrandomized studies it does not, however, account for systematic differences between treatment groups (with respect to covariates like age, BMI, etc.), it might also be misleading or even giving a biased impression. Further advantages of the LSOS include the multicenter setting and prospective collection of data, and the use of established questionnaires on DLSS.

A limitation of the present study was that the treatment strategy (with or without fusion) was not randomized. If unaccounted for, this could have led to biased estimate of the effect of fusion. To account for this problem, adjustment for potential confounding was performed, however, only for measured covariates. Consequently, unmeasured confounders could have affected the difference between the two groups and hampered direct comparisons with RCTs. Other limitations of the study were its small sample size and that only a third of the included patients have already reached 36 months follow-up. In addition, we do not have any data regarding operating time, length of hospital stay, or the bone matrix density. These parameters might have influenced our results.

\section{CONCLUSION}

Among the patients with DLSS our study confirms that in the two groups, decompression alone and decompression with fusion, patients distinctively benefited from surgical treatment. When adjusted for confounders, fusion surgery was not associated with a more favorable outcome in both SSM scores as compared to decompression surgery alone.

\section{Key Points}

aim of the present study was to assess which surgical management provides better outcome in degenerative spinal stenosis cases with spondylolisthesis: decompression alone or decompression with fusion.

$\square$ The LSOS is conducted as a prospective cohort study at eight medical centers with approximately two million inhabitants in the over regional area.

$\square$ One hundred thirty-one patients undergoing decompression surgery alone $(n=85)$ or decompression with fusion surgery $(n=46)$ were included in the present study.

$\square$ In the multiple mixed effects model the adjusted effect of fusion compared with decompression alone surgery on SSM symptoms was $0.06(95 \%$ $\mathrm{Cl}:-0.16-0.27)$ and $-0.07(95 \% \mathrm{Cl}:-0.25-0.10)$ on SSM function, respectively.

$\square$ When adjusted for confounders, fusion surgery was not associated with a more favorable outcome in both SSM scores as compared to decompression alone surgery.

\section{Acknowledgments}

The authors thank the Baugarten Foundation, the Helmut Horten Foundation, the Pfizer-Foundation for geriatrics and research in geriatrics, the Symphasis Charitable Foundation, and the OPO Foundation for their support. 
Supplemental digital content is available for this article. Direct URL citations appearing in the printed text are provided in the HTML and PDF version of this article on the journal's Web site (www.spinejournal.com).

\section{References}

1. Ishimoto Y, Yoshimura N, Muraki S, et al. Associations between radiographic lumbar spinal stenosis and clinical symptoms in the general population: the Wakayama Spine Study. Osteoarthritis Cartilage 2013;21:783-8.

2. Benoist M. The natural history of lumbar degenerative spinal stenosis. Joint Bone Spine 2002;69:450-7.

3. Kreiner DS, Shaffer WO, Baisden JL, et al. An evidence-based clinical guideline for the diagnosis and treatment of degenerative lumbar spinal stenosis (update). Spine J 2013;13:734-43.

4. Deyo RA, Mirza SK, Martin BI, et al. Trends, major medical complications, and charges associated with surgery for lumbar spinal stenosis in older adults. JAMA 2010;303:1259-65.

5. Davis $\mathrm{H}$. Increasing rates of cervical and lumbar spine surgery in the United States, 1979-1990. Spine (Phila Pa 1976) 1994;19:1117-23; discussion 23-24.

6. Ciol MA, Deyo RA, Howell E, et al. An assessment of surgery for spinal stenosis: time trends, geographic variations, complications, and reoperations. J Am Geriatr Soc 1996;44:285-90.

7. Grob D, Humke T, Dvorak J. Degenerative lumbar spinal stenosis. Decompression with and without arthrodesis. J Bone Joint Surg Am 1995;77:1036-41.

8. Cavusoglu H, Turkmenoglu O, Kaya RA, et al. Efficacy of unilateral laminectomy for bilateral decompression in lumbar spinal stenosis. Turk Neurosurg 2007;17:100-8.

9. May S, Comer C. Is surgery more effective than non-surgical treatment for spinal stenosis, and which non-surgical treatment is more effective? A systematic review. Physiotherapy 2013; 99:12-20.

10. Kovacs FM, Urrutia G, Alarcon JD. Surgery versus conservative treatment for symptomatic lumbar spinal stenosis: a systematic review of randomized controlled trials. Spine (Phila Pa 1976) 2011;36:E1335-51.

11. Weinstein JN, Lurie JD, Olson PR, et al. United States' trends and regional variations in lumbar spine surgery: 1992-2003. Spine (Phila Pa 1976) 2006;31:2707-14.

12. Atlas SJ, Keller RB, Wu YA, et al. Long-term outcomes of surgical and nonsurgical management of lumbar spinal stenosis: 8 to 10 year results from the maine lumbar spine study. Spine (Phila Pa 1976) 2005;30:936-43.

13. Atlas SJ, Keller RB, Robson D, et al. Surgical and nonsurgical management of lumbar spinal stenosis: four-year outcomes from the maine lumbar spine study. Spine (Phila Pa 1976) 2000; 25:556-62.

14. Malmivaara A, Slatis P, Heliovaara M, et al. Surgical or nonoperative treatment for lumbar spinal stenosis? A randomized controlled trial. Spine (Phila Pa 1976) 2007;32:1-8.

15. Forsth P, Olafsson G, Carlsson T, et al. A randomized, controlled trial of fusion surgery for lumbar spinal stenosis. N Engl J Med 2016;374:1413-23.

16. Yone K, Sakou T, Kawauchi Y, et al. Indication of fusion for lumbar spinal stenosis in elderly patients and its significance. Spine (Phila Pa 1976) 1996;21:242-8.

17. Herkowitz HN, Kurz LT. Degenerative lumbar spondylolisthesis with spinal stenosis. A prospective study comparing decompression with decompression and intertransverse process arthrodesis. $J$ Bone Joint Surg Am 1991;73:802-8.

18. Ghogawala Z, Dziura J, Butler WE, et al. Laminectomy plus fusion versus laminectomy alone for lumbar spondylolisthesis. $N$ Engl J Med 2016;374:1424-34.
19. Andreisek G, Deyo RA, Jarvik JG, et al. Consensus conference on core radiological parameters to describe lumbar stenosis-an initiative for structured reporting. Eur Radiol 2014;24: 3224-32.

20. Stucki G, Liang MH, Fossel AH, et al. Relative responsiveness of condition-specific and generic health status measures in degenerative lumbar spinal stenosis. J Clin Epidemiol 1995;48: 1369-78

21. Tuli SK, Yerby SA, Katz JN. Methodological approaches to developing criteria for improvement in lumbar spinal stenosis surgery. Spine (Phila Pa 1976) 2006;31:1276-80.

22. Zucherman JF, Hsu KY, Hartjen CA, et al. A multicenter, prospective, randomized trial evaluating the X STOP interspinous process decompression system for the treatment of neurogenic intermittent claudication: two-year follow-up results. Spine (Phila $\mathrm{Pa}$ 1976) 2005;30:1351-8.

23. Hansraj KK, O’Leary PF, Cammisa FP Jr, et al. Decompression, fusion, and instrumentation surgery for complex lumbar spinal stenosis. Clin Orthop Relat Res 2001;18-25.

24. Fokter SK, Yerby SA. Patient-based outcomes for the operative treatment of degenerative lumbar spinal stenosis. Eur Spine J 2006;15:1661-9.

25. Hinz A, Klaiberg A, Brahler E, et al. The Quality of Life Questionnaire EQ-5D: modelling and norm values for the general population [in German]. Psychother Psychosom Med Psychol 2006;56:42-8.

26. Roland M, Morris R. A study of the natural history of low-back pain. Part II: development of guidelines for trials of treatment in primary care. Spine (Phila Pa 1976) 1983;8:145-50.

27. Miller MD, Paradis CF, Houck PR, et al. Rating chronic medical illness burden in geropsychiatric practice and research-application of the cumulative illness rating-scale. Psychiat Res 1992;41:237-48.

28. Ulrich NH1, Burgstaller JM, Held U, et al., LSOS Study Group. The Influence of Single-level Versus Multilevel Decompression on the Outcome in Multisegmental Lumbar Spinal Stenosis: Analysis of the Lumbar Spinal Outcome Study (LSOS) Data. Clin Spine Surg 2017; Jan 4. doi: 10.1097/BSD.0000000000000469. [Epub ahead of print] PMID: 28059949.

29. Kenward MG, Roger JH. Small sample inference for fixed effects from restricted maximum likelihood. Biometrics 1997; 53:983-97.

30. R Core Team. R: A Language and Environment for Statistical Computing. Vienna, Austria: R Foundation for Statistical Computing, 2013.

31. Forsth P, Michaelsson K, Sanden B. Does fusion improve the outcome after decompressive surgery for lumbar spinal stenosis? A two-year follow-up study involving 5390 patients. Bone Joint J 2013;95b:960-5.

32. Athiviraham A, Yen D. Is spinal stenosis better treated surgically or nonsurgically? Clin Orthop Relat Res 2007;458:90-3.

33. Pratt RK, Fairbank JCT, Virr A. The reliability of the Shuttle Walking Test, the Swiss Spinal Stenosis Questionnaire, the Oxford Spinal Stenosis Score, and the Oswestry Disability Index in the assessment of patients with lumbar spinal stenosis. Spine 2002;27:84-91.

34. Burgstaller JM, Porchet F, Steurer J, et al. Arguments for the choice of surgical treatments in patients with lumbar spinal stenosis-a systematic appraisal of randomized controlled trials. BMC Musculoskelet Disord 2015;16:96.

35. Kornblum MB, Fischgrund JS, Herkowitz HN, et al. Degenerative lumbar spondylolisthesis with spinal stenosis: a prospective longterm study comparing fusion and pseudarthrosis. Spine (Phila $\mathrm{Pa}$ 1976) 2004;29:726-33; discussion 33-34.

36. Kepler CK, Vaccaro AR, Hilibrand AS, et al. National trends in the use of fusion techniques to treat degenerative spondylolisthesis. Spine 2014;39:1584-9. 